\title{
Stem Blight of Blueberry Caused by Lasiodiplodia vaccinii sp. nov. in China
}

\author{
Lin Zhao, ${ }^{1}$ Yu Wang, ${ }^{1}$ Wei He, ${ }^{2}$ and Ying Zhang ${ }^{1, \dagger}$ \\ ${ }^{1}$ Institute of Microbiology, Beijing Forestry University, Beijing 100083, People's Republic of China \\ ${ }^{2}$ Beijing Key Laboratory for Forest Pest Control, Beijing Forestry University, Beijing 100083, People's Republic of China
}

\begin{abstract}
Blueberries (Vaccinium spp.) are largely cultivated in China because of their nutritional benefits and economic value. Blueberry stem blight caused by members of the Botryosphaeriaceae has become one of the most severe diseases affecting blueberry cultivation in China. In this study, we examined the causal agent of blueberry stem blight at commercial greenhouse farms in the suburban area of Beijing, China. In total, 37 isolates of Botryosphaeriaceae were obtained from 100 stem blight samples of blueberry. Twelve of 37 strains were morphologically consistent with the genus Lasiodiplodia, showing ellipsoid to ovoid, one-celled, hyaline conidia that sometimes turned brown, with median septa and longitudinal striations when mature. These 12 strains were identified as belonging to a novel fungal species, Lasiodi-

and translation elongation factor-1 $\alpha$ gene sequences as well as morphological characteristics. Pathogenicity tests indicated that $L$. vaccinii can cause twig blight on blueberry seedlings in the greenhouse. Mycelial growth of $L$. vaccinii occurred at $\mathrm{pH}$ values ranging from 3.0 to 10.0, with an optimum at 6.2 , and at temperatures from 15 to $40^{\circ} \mathrm{C}$, with an optimum at $30.3^{\circ} \mathrm{C}$. Of the seven carbon sources tested, sucrose, fructose, and glucose were all highly efficient in supporting the mycelial growth of $L$. vaccinii, and xylose was the least effective. Of six nitrogen sources tested, yeast extract and tryptone best promoted mycelial growth of $L$. vaccinii. The ability of $L$. vaccinii to grow at high temperatures may help to explain its occurrence in Beijing greenhouses in this study.
\end{abstract} plodia vaccinii, based on phylogenetic analysis of the concatenated internal transcribed spacer, RNA polymerase II gene, $\beta$-tubulin gene,
Keywords: fruit, fungi, small fruits, tree fruits, pathogen diversity
Blueberries (Vaccinium spp.), one of the most nutritious and antioxidant-rich fruits, can enhance memory and prevent heart disease (Shi and Liu 2009). Because of their health benefits and economic value, blueberries are commercially cultivated worldwide, including in the United States, Canada, and Europe (Evans and Ballen 2014; Popović et al. 2018). In China, blueberry cultivation started in 1981, and there has been a significant increase in the area under cultivation, with $>31,210$ ha and productivity of 43,244 tons per year over the last 10 years ( $\mathrm{Li}$ et al. 2016).

The Botryosphaeriaceae family is composed of versatile and cosmopolitan species associated with a variety of plants, including Vaccinium spp., as pathogens, endophytes, or saprophytes (Phillips et al. 2013; Slippers and Wingfield 2007). Members of the Botryosphaeriaceae have been reported as causal agents of cankers, dieback, fruit blights, and seed rots of woody plants at many locations across the world (Chen et al. 2015; Milholland 1972a, b; Phillips et al. 2006; Tang et al. 2012; van Niekerk et al. 2004). For instance, shoot blight of the genus Pistacia caused by botryosphaeriaceous fungi is regarded as a major threat to the pistachio industry in the United States and Greece (Chen et al. 2014, 2015; Michailides and Morgan 1992, 2004). Botryosphaeria dothidea is the causal agent of Botryosphaeria canker of apple and apple ring rot, which is one of the most

${ }^{\dagger}$ Corresponding author: Y. Zhang; yzhang@bjfu.edu.cn

L. Zhao and Y. Wang contributed equally to this work.

Funding: This work was supported by Fundamental Research Funds for the Central Universities grant 2016ZCQ04; National Natural Science Foundation of China (NSFC) General Program and grants 31770015 and 31370063; NSFC Projects of International Cooperation and Exchanges grant 3155461143028; and National Science and Technology Foundation Project grant 2014FY210400.

The author(s) declare no conflict of interest.

Accepted for publication 18 March 2019.

(c) 2019 The American Phytopathological Society severe diseases affecting apple production in China (Tang et al. 2012).

The botryosphaeriaceous fungi have been widely regarded as the main causal agents of blueberry stem blight (Boyzo-Marin et al. 2016; Creswell and Milholland 1988; Espinoza et al. 2009; Koike et al. 2014; Milholland 1972 a, b; Popović et al. 2018; Smith 2004; Tennakoon et al. 2018; Witcher and Clayton 1962; Wright and Harmon 2009, 2010; Xu 2016; Xu et al. 2015; Yu et al. 2012, $2013 \mathrm{a}, \mathrm{b})$. Symptoms associated with blueberry stem blight include wilting of the twigs and infected woody tissue turning brown, and pathogens invade the xylem, resulting in mortality of whole plants (Milholland 1972b; Wright and Harmon 2010; Xu 2016; Xu et al. 2015). Several members of the Botryosphaeriaceae have been reported as causing stem blight or dieback of blueberries in China, including B. dothidea, Neofusicoccum parvum, Neofusicoccum vitifusiforme, Lasiodiplodia theobromae, Lasiodiplodia pseudotheobromae, and Lasiodiplodia chinensis (Dou et al. 2017b; Kong et al. 2010; Wang et al. 2016; Xu 2016; Xu et al. 2015; Yu et al. 2012, 2013a, b).

Stem blight and branch blight have occurred on highbush blueberries (Vaccinium corymbosum L.) at commercial greenhouse farms in the suburbs of Beijing, China. Typical symptoms of the disease are stem blight and dieback with lesions extending along entire branches. Infected stems have a light brown to brown pigmentation. The dead leaves stay on the recently killed stems as a brown "flag." The disease seriously affects the growth of blueberry plants, fruit quality, and productivity, with crop damage ranging from 15 to $25 \%$ based on our observations. The objectives of this study were to (i) identify the pathogenic fungi causing blueberry stem blight disease on the basis of morphological characteristics and multigene sequence analysis, (ii) determine their pathogenicity on blueberry, and (iii) characterize their growth at different temperatures and $\mathrm{pH}$ and their capacity to utilize different carbon and nitrogen sources.

\section{Materials and Methods}

Sample collection and fungal isolation. Samples were collected in the greenhouse at Huiyuan Juice Blueberry Production Garden in the suburb area of Beijing, China. Diseased or dead stems (about $30 \mathrm{~cm}$ in length) were taken from blueberry branches 
(V. corymbosum) in October 2017. In total, 100 samples were collected from 50 bushes (with one dead twig and one diseased twig for each bush). Wood segments $(0.5 \times 0.5 \times 0.2 \mathrm{~cm})$ cut from the disease lesion boundary or dead tissue were surface disinfected with $75 \%$ ethanol for $30 \mathrm{~s}$ and rinsed three times with sterile water; then, they were incubated on malt extract agar (MEA; 2\%) for isolation of fungal strains (Pavlic et al. 2004; Xu et al. 2015). Petri dishes were incubated in the dark at $28^{\circ} \mathrm{C}$ until the fungal colonies were observed. Colonies resembling the Botryosphaeriaceae were obtained by transferring hyphal tips from colony margins to MEA plates. Isolates grown on MEA in the dark were kept at $28^{\circ} \mathrm{C}$ to determine colony characteristics.

Morphological characterization. Fungal colonies were initially identified based on morphological characteristics, including colony, conidiogenous cells, and conidia. To induce sporulation, isolates were cultivated on water agar (WA; $2 \%$; Biolab, S.A.) with autoclaved pine needles placed on the medium and incubated at $25^{\circ} \mathrm{C}$ under near-ultraviolet light (mainly $340 \mathrm{~nm}$ ) (Dou et al. 2017a). Pycnidia produced on the pine needles were morphologically described and characterized following the protocol of Dou et al. (2017a, b). Measurements of 20 paraphyses, 20 conidiogenous cells, and 50 conidia were made by immersing pycnidia in water under a microscope (Nikon Eclipse E600). Fungal isolates and specimens were deposited at Beijing Forestry University, with duplicates at the China General Microbiological Culture Collection Center (CGMCC) and the Mycological Herbarium of the Institute of Microbiology, Chinese Academy of Sciences (HMAS) (Table 1).

Table 1. GenBank accession numbers of isolates included in this study

\begin{tabular}{|c|c|c|c|c|c|}
\hline \multirow[b]{2}{*}{ Species } & \multirow[b]{2}{*}{ Isolate } & \multicolumn{4}{|c|}{ GenBank accession number ${ }^{\mathbf{z}}$} \\
\hline & & ITS & tef1- $\alpha$ & $T U B$ & $R P B 2$ \\
\hline Botryosphaeria dothidea & CBS 115476 & AY236949 & AY236898 & N/A & N/A \\
\hline Botryosphaeria dothidea & CGMCC 3.19257 & MK085913 & MK085916 & N/A & N/A \\
\hline Botryosphaeria dothidea & CGMCC 3.19258 & MK085912 & MK085915 & N/A & N/A \\
\hline Botryosphaeria dothidea & CGMCC 3.19259 & MK085911 & MK085914 & N/A & N/A \\
\hline Diplodia mutila & CMW 7060 & AY236955 & AY236904 & AY236933 & EU339574 \\
\hline Diplodia seriata & CBS 112555 & AY259094 & AY573220 & DQ458856 & N/A \\
\hline Lasiodiplodia americana & CERC 1961 & KP217059 & KP217067 & KP217075 & N/A \\
\hline Lasiodiplodia americana & CERC 1960 & KP217058 & KP217066 & KP217074 & N/A \\
\hline Lasiodiplodia avicenniae & CMW 41467 & KP860835 & KP860680 & KP860758 & KU587878 \\
\hline Lasiodiplodia avicenniae & LAS 199 & KU587957 & KU587947 & KU587868 & KU587880 \\
\hline Lasiodiplodia brasiliense & CMM 2321 & KC484797 & KC481528 & N/A & N/A \\
\hline Lasiodiplodia brasiliense & CGMCC 3.17966 & KY783475 & KY848612 & KY848556 & KY848595 \\
\hline Lasiodiplodia brasiliense & CMM 4015 & JX464063 & JX464049 & N/A & N/A \\
\hline Lasiodiplodia brasiliense & CMW 35884 & KU887094 & KU886972 & KU887466 & KU696345 \\
\hline Lasiodiplodia bruguierae & CMW 41470 & KP860833 & KP860678 & KP860756 & KU587875 \\
\hline Lasiodiplodia bruguierae & CMW 42480 & KP860832 & KP860677 & KP860755 & KU587876 \\
\hline Lasiodiplodia caatinguensis & CMM 1325 & KT154760 & KT008006 & KT154767 & N/A \\
\hline Lasiodiplodia caatinguensis & IBL 381 & KT154757 & KT154751 & KT154764 & N/A \\
\hline Lasiodiplodia chinensis & CGMCC 3.18061 & KX499889 & KX499927 & KX500002 & KX499965 \\
\hline Lasiodiplodia chinensis & CGMCC 3.18063 & KX499891 & KX499929 & KX500004 & KX499967 \\
\hline Lasiodiplodia citricola & IRAN $1522 \mathrm{C}$ & GU945354 & GU945340 & KU887505 & KU696351 \\
\hline Lasiodiplodia citricola & IRAN 1521C & GU945353 & GU945339 & KP872406 & KP872456 \\
\hline Lasiodiplodia crassispora & WAC12533 & DQ103550 & DQ103557 & KU887506 & KU696353 \\
\hline Lasiodiplodia crassispora & CMW 13488 & DQ103552 & DQ103559 & KU887507 & KU696352 \\
\hline Lasiodiplodia egyptiacae & BOT 29 & JN814401 & JN814428 & N/A & N/A \\
\hline Lasiodiplodia euphorbicola & CMW 33350 & KU887149 & KU887026 & KU887455 & KU696346 \\
\hline Lasiodiplodia euphorbicola & CMW 36231 & KU887187 & KU887063 & KU887494 & KU696347 \\
\hline Lasiodiplodia euphorbicola & CMM 3609 & KF234543 & KF226689 & KF254926 & N/A \\
\hline Lasiodiplodia exigua & CBS 137785 & KJ638317 & KJ638336 & KU887509 & KU696355 \\
\hline Lasiodiplodia exigua & BL 184 & KJ638318 & KJ638337 & N/A & N/A \\
\hline Lasiodiplodia gilanensis & IRAN $1523 \mathrm{C}$ & GU945351 & GU945342 & KU887511 & KU696357 \\
\hline Lasiodiplodia gilanensis & IRAN $1501 \mathrm{C}$ & GU945352 & GU945341 & KU887510 & KU696356 \\
\hline Lasiodiplodia gonubiensis & CMW 14077 & AY639595 & DQ103566 & DQ458860 & KU696359 \\
\hline Lasiodiplodia gonubiensis & CMW 14078 & AY639594 & DQ103567 & EU673126 & KU696358 \\
\hline Lasiodiplodia gravistriata & CMM 4564 & KT250949 & KT250950 & N/A & N/A \\
\hline Lasiodiplodia gravistriata & CMM 4565 & KT250947 & KT266812 & N/A & N/A \\
\hline Lasiodiplodia hyalina & CGMCC 3.17975 & KX499879 & KX499917 & KX499992 & KX499955 \\
\hline Lasiodiplodia hormozganensis & IRAN $1500 \mathrm{C}$ & GU945355 & GU945343 & KU887515 & KU696361 \\
\hline Lasiodiplodia hormozganensis & IRAN 1498C & GU945356 & GU945344 & KU887514 & KU696360 \\
\hline Lasiodiplodia indica & IBP 01 & AP012032 & N/A & N/A & N/A \\
\hline Lasiodiplodia iraniensis & IRAN 1520C & GU945348 & GU945336 & KU887516 & KU696363 \\
\hline Lasiodiplodia iraniensis & IRAN 1502C & GU945347 & GU945335 & KU887517 & KU696362 \\
\hline Lasiodiplodia jatrophicola & CMM 3610 & KF234544 & KF226690 & KF254927 & N/A \\
\hline Lasiodiplodia jatrophicola & CMW 36237 & KU887121 & KU886998 & KU887499 & KU696348 \\
\hline Lasiodiplodia jatrophicola & CMW 36239 & KU887123 & KU887000 & KU887501 & KU696349 \\
\hline \multirow{2}{*}{ Lasiodiplodia laeliocattleyae } & CBS 130992 & JN814397 & JN814424 & KU887508 & KU696354 \\
\hline & & & & \multicolumn{2}{|c|}{ (Continued on next page) } \\
\hline
\end{tabular}

${ }^{y}$ Newly generated sequences are indicated in bold.

${ }^{\mathrm{z}}$ ITS, internal transcribed spacer; RPB2, RNA polymerase II; tef1- $\alpha$, translation elongation factor- $1 \alpha ; T U B, \beta$-tubulin, and N/A = not available. 
Molecular characterization. DNA was extracted from mycelia grown on MEA plates using a CTAB plant genome DNA fast extraction kit (Aidlab Biotechnologies Co., Ltd). The internal transcribed spacer (ITS) ribosomal DNA region was amplified and sequenced with primers ITS-1 and ITS-4 (White et al. 1990), the RNA polymerase II gene $(R P B 2)$ with primers RPB2-LasF and RPB2-LasR (Cruywagen et al. 2017), the $\beta$-tubulin gene (TUB) with primers $\mathrm{Bt} 2 \mathrm{a}$ and $\mathrm{Bt} 2 \mathrm{~b}$ (Glass and Donaldson 1995), and the translation elongation factor- $1 \alpha($ tefl- $\alpha)$ with primers EF1-688F and EF1-986R (Alves et al. 2008; Carbone et al. 1999). PCR amplification and sequencing followed the protocol of Zhang et al. (2009).

DNA sequences of concatenated ITS, RPB2, TUB, and tefl- $\alpha$ loci were analyzed to investigate the phylogenetic relationships among Lasiodiplodia species using DNA sequences available from
GenBank (https://www.ncbi.nlm.nih.gov/genbank/) as well as the sequences generated herein (Table 1). Sequence alignment was performed with MEGA v. 6, and gaps were manually adjusted to optimize the alignment (Tamura et al. 2013). Analyses of maximum parsimony were performed with gaps being treated as missing data using PAUP v. $4.0 \mathrm{~b} 10$ (Swofford 2002). Clade stability was evaluated in a bootstrap analysis with 1,000 replicates, random sequence additions with the maxtrees parameter set to 1,000, and other parameters left at default values as implemented in PAUP. Trees were viewed in TreeView v1.6.6 (Page 1996).

Pathogenicity testing. Mycelia and conidia of three isolates of Lasiodiplodia vaccinii (CGMCC3.19022, CGMCC3.19023, and CGMCC3.19024) and three of B. dothidea (CGMCC3.19259, CGMCC3.19258, and CGMCC3.19257) obtained in this study were

Table 1. (Continued from previous page)

\begin{tabular}{|c|c|c|c|c|c|}
\hline \multirow[b]{2}{*}{ Species } & \multirow[b]{2}{*}{ Isolate } & \multicolumn{4}{|c|}{ GenBank accession number ${ }^{\mathrm{z}}$} \\
\hline & & ITS & tef1- $\alpha$ & $T U \boldsymbol{B}$ & $R P B 2$ \\
\hline Lasiodiplodia lignicola & CBS 134112 & JX646797 & KU887003 & JX646845 & KU696364 \\
\hline Lasiodiplodia lignicola & MFLUCC 11-0656 & JX646798 & N/A & JX646846 & N/A \\
\hline Lasiodiplodia macrospora & CMM 3833 & KF234557 & KF226718 & KF254941 & N/A \\
\hline Lasiodiplodia mahajangana & CMW 27818 & FJ900596 & FJ900642 & FJ900631 & KU696366 \\
\hline Lasiodiplodia mahajangana & CMW 27801 & FJ900595 & FJ900641 & FJ900630 & KU696365 \\
\hline Lasiodiplodia margaritacea & CBS 122519 & EU144050 & EU144065 & KU887520 & KU696367 \\
\hline Lasiodiplodia margaritacea & CBS 122065 & EU144051 & EU144066 & N/A & N/A \\
\hline Lasiodiplodia mediterranea & CBS 137783 & KJ638312 & KJ638331 & KU887521 & KU696368 \\
\hline Lasiodiplodia mediterranea & CBS 137784 & KJ638311 & KJ638330 & KU887522 & KU696369 \\
\hline Lasiodiplodia missouriana & UCD 2193MO & HQ288225 & HQ288267 & HQ288304 & KU696370 \\
\hline Lasiodiplodia missouriana & UCD 2199MO & HQ288226 & HQ288268 & HQ288305 & KU696371 \\
\hline Lasiodiplodia parva & CBS 456.78 & EF622083 & EF622063 & KU887523 & KU696372 \\
\hline Lasiodiplodia parva & CBS 494.78 & EF622084 & EF622064 & EU673114 & KU696373 \\
\hline Lasiodiplodia plurivora & STE-U 5803 & EF445362 & EF445362 & EF445362 & EF445362 \\
\hline Lasiodiplodia plurivora & STE-U 4583 & AY343482 & EF445396 & KU887525 & KU696375 \\
\hline Lasiodiplodia pontae & CMM 1277 & KT151794 & KT151791 & KT151797 & $\mathrm{N} / \mathrm{A}$ \\
\hline Lasiodiplodia pseudotheobromae & CBS 116459 & EF622077 & EF622057 & EU673111 & KU696376 \\
\hline Lasiodiplodia pseudotheobromae & CGMCC 3.18047 & KX499876 & KX499914 & KX499989 & KX499952 \\
\hline Lasiodiplodia pyriformis & CBS 121771 & EU101308 & EU101353 & KU887528 & KU887528 \\
\hline Lasiodiplodia pyriformis & CBS 121770 & EU101307 & EU101352 & KU887527 & KU696378 \\
\hline Lasiodiplodia rubropurpurea & WAC 12535 & DQ103553 & DQ103571 & EU673136 & KU696380 \\
\hline Lasiodiplodia rubropurpurea & WAC 12536 & DQ103554 & DQ103572 & KU887530 & KU696381 \\
\hline Lasiodiplodia sterculiae & CBS 342.78 & KX464140 & KX464634 & KX464908 & KX463989 \\
\hline Lasiodiplodia subglobosa & CMM 4046 & KF234560 & KF226723 & KF254944 & N/A \\
\hline Lasiodiplodia subglobosa & CMM 3872 & KF234558 & KF226721 & KF254942 & N/A \\
\hline Lasiodiplodia thailandica & CPC 22795 & KJ193637 & KJ193681 & N/A & N/A \\
\hline Lasiodiplodia thailandica & CP 22755 & KM006433 & KM006464 & N/A & N/A \\
\hline Lasiodiplodia theobromae & CBS 111530 & EF622074 & EF622054 & KU887531 & KU696382 \\
\hline Lasiodiplodia theobromae & CBS 164.96 & AY640255 & AY640258 & KU887532 & KU696383 \\
\hline Lasiodiplodia vaccinii & CGMCC 3.19022 & HM330318 & HM330321 & MH330324 & HM330327 \\
\hline Lasiodiplodia vaccinii & CGMCC 3.19023 & HM330319 & HM330322 & HM330326 & HM330329 \\
\hline Lasiodiplodia vaccinii & CGMCC 3.19024 & HM330320 & HM330323 & HM330325 & HМ330328 \\
\hline Lasiodiplodia vaccinii & CGMCC 3.19248 & MK157131 & MK157158 & MK157149 & MK157140 \\
\hline Lasiodiplodia vaccinii & CGMCC 3.19249 & MK157132 & MK157159 & MK157150 & MK157141 \\
\hline Lasiodiplodia vaccinii & CGMCC 3.19250 & MK157133 & MK157160 & MK157151 & MK157142 \\
\hline Lasiodiplodia vaccinii & CGMCC 3.19251 & MK157134 & MK157161 & MK157152 & MK157143 \\
\hline Lasiodiplodia vaccinii & CGMCC 3.19252 & MK157135 & MK157162 & MK157153 & MK157144 \\
\hline Lasiodiplodia vaccinii & CGMCC 3.19253 & MK157136 & MK157163 & MK157154 & MK157145 \\
\hline Lasiodiplodia vaccinii & CGMCC 3.19254 & MK157137 & MK157164 & MK157155 & MK157146 \\
\hline Lasiodiplodia vaccinii & CGMCC 3.19255 & MK157138 & MK157165 & MK157156 & MK157147 \\
\hline Lasiodiplodia vaccinii & CGMCC 3.19256 & MK157139 & MK157166 & MK157157 & MK157148 \\
\hline Lasiodiplodia venezuelensis & WAC 12539 & DQ103547 & DQ103568 & KU887533 & KU696384 \\
\hline Lasiodiplodia venezuelensis & WAC 12540 & DQ103548 & DQ103569 & KU887534 & KU887534 \\
\hline Lasiodiplodia viticola & UCD 2553AR & HQ288227 & HQ288269 & HQ288306 & KU696385 \\
\hline Lasiodiplodia viticola & UCD $2604 \mathrm{MO}$ & HQ288228 & HQ288270 & HQ288307 & KU696386 \\
\hline Lasiodiplodia vitis & CBS 124060 & KX464148 & KX464642 & KX464917 & KX463994 \\
\hline
\end{tabular}


used to conduct pathogenicity testing. The pathogenicity test was performed on 4-year-old blueberry (cultivar O'Neal) plants obtained from seeds kept in a greenhouse at $28^{\circ} \mathrm{C}$ and $99 \%$ relative humidity. On healthy plants, 2-year-old twigs to be used for inoculation were surface disinfected with $75 \%$ ethanol for $1 \mathrm{~min}$. The bark surface of each disinfected twig was stabbed 10 times with a sterilized inoculating needle within a region $5 \mathrm{~mm}$ in length to a depth of $2 \mathrm{~mm}$ (Lin et al. 2011). For mycelial inoculation, a 5mm-diameter MEA plug with mycelia was taken from a 3-dayold colony and inoculated onto the wounded twigs. For conidial

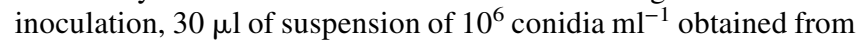
pycnidia was crushed in sterile water and drop inoculated onto the wounded site (Espinoza et al. 2009). All of the inoculated twigs were covered with parafilm. Three replicates were conducted for each isolate. Noncolonized MEA plugs and sterile water were used as negative controls. Pathogenicity was determined by the length of the necrotic lesion caused by the tested isolates, which was measured 3 weeks after inoculation. Fungal isolates were reisolated from the infected tissue, and morphological characterization and DNA sequence comparisons were conducted to fulfill Koch's postulates. Mean comparisons were conducted using Tukey's honest significant difference (HSD) test $(\alpha=0.05)$ in $\mathrm{R}$ (Version 3.2.2; R Inc.).

Temperature and $\mathbf{p H}$ tests. Because all of the 12 isolates of L. vaccinii showed similar growth characteristics, we used the type strain (CGMCC3.19022) to evaluate the effects of temperature and $\mathrm{pH}$ on colony growth on MEA plates. Temperatures tested ranged from 5 to $40^{\circ} \mathrm{C}$ at $5^{\circ} \mathrm{C}$ intervals (i.e., $5,10,15,20,25,30,35$, and $40^{\circ} \mathrm{C}$ ). To clarify the effect of $\mathrm{pH}$ on radial mycelial growth, MEA media were adjusted with $0.1 \mathrm{M} \mathrm{NaOH}$ and $0.1 \mathrm{M} \mathrm{HCl}$ to obtain
$\mathrm{pH}$ values from 2.0 to 12.0 at a $\mathrm{pH} 1.0$ interval (i.e., 2.0, 3.0, 4.0, 5.0, 6.0, 7.0, 8.0, 9.0, 10.0, 11.0, and 12.0). A 5-mm-diameter mycelial plug was placed in the center of a $90-\mathrm{mm}$ petri dish with MEA medium and incubated at $28^{\circ} \mathrm{C}$ in the dark, with three replicates for each treatment. The effects of $\mathrm{pH}$ and temperature on mycelial growth were determined by measuring the colony diameters after 24 and $48 \mathrm{~h}$ of incubation, and the data were converted to radial growth in millimeters (Xu et al. 2015). Data were analyzed in IBM SPSS Statistics (V22.0, IBM Inc.) to select the model that best fit the individual data points, and SPSS was used to confirm the selected model. The optimal temperature and $\mathrm{pH}$ value of the regression curves were calculated based on the regression equations generated by IBM SPSS Statistics.

Carbon and nitrogen source tests. To investigate the utilization of nitrogen and carbon sources, the representative strain of $L$. vaccinii (CGMCC3.19022) was incubated in the dark at $28^{\circ} \mathrm{C}$ on WA medium for 3 days. Czapek-Dox medium was used as the basic medium (sodium nitrate $3 \mathrm{~g}$, dipotassium hydrogen phosphate $1 \mathrm{~g}$, magnesium sulfate $0.5 \mathrm{~g}$, potassium chloride $0.5 \mathrm{~g}$, ferrous sulfate $0.01 \mathrm{~g}$, sucrose $30 \mathrm{~g}$, agar $20 \mathrm{~g}$, and distilled water to complete $1,000 \mathrm{ml}$ ) (Czapek 1902, 1903; Dox 1910). The $30 \mathrm{~g}$ sucrose was replaced with $30 \mathrm{~g}$ fructose, galactose, glucose, maltose, sorbitol, sucrose, or xylose to test these compounds as carbon sources. The $3 \mathrm{~g}$ sodium nitrate was replaced with $3 \mathrm{~g}$ ammonium nitrate, ammonium sulfate, ammonium tartrate, glycine, tryptone, or yeast extract to determine growth on different nitrogen sources. A 5-mm-diameter WA plug of mycelia was transferred to the center of each sole carbon source medium and sole nitrogen source medium. Colony growth was determined by measuring the colony diameters after incubation for 24 and $48 \mathrm{~h}$ at $28^{\circ} \mathrm{C}$ in the dark, and the results were subsequently converted to
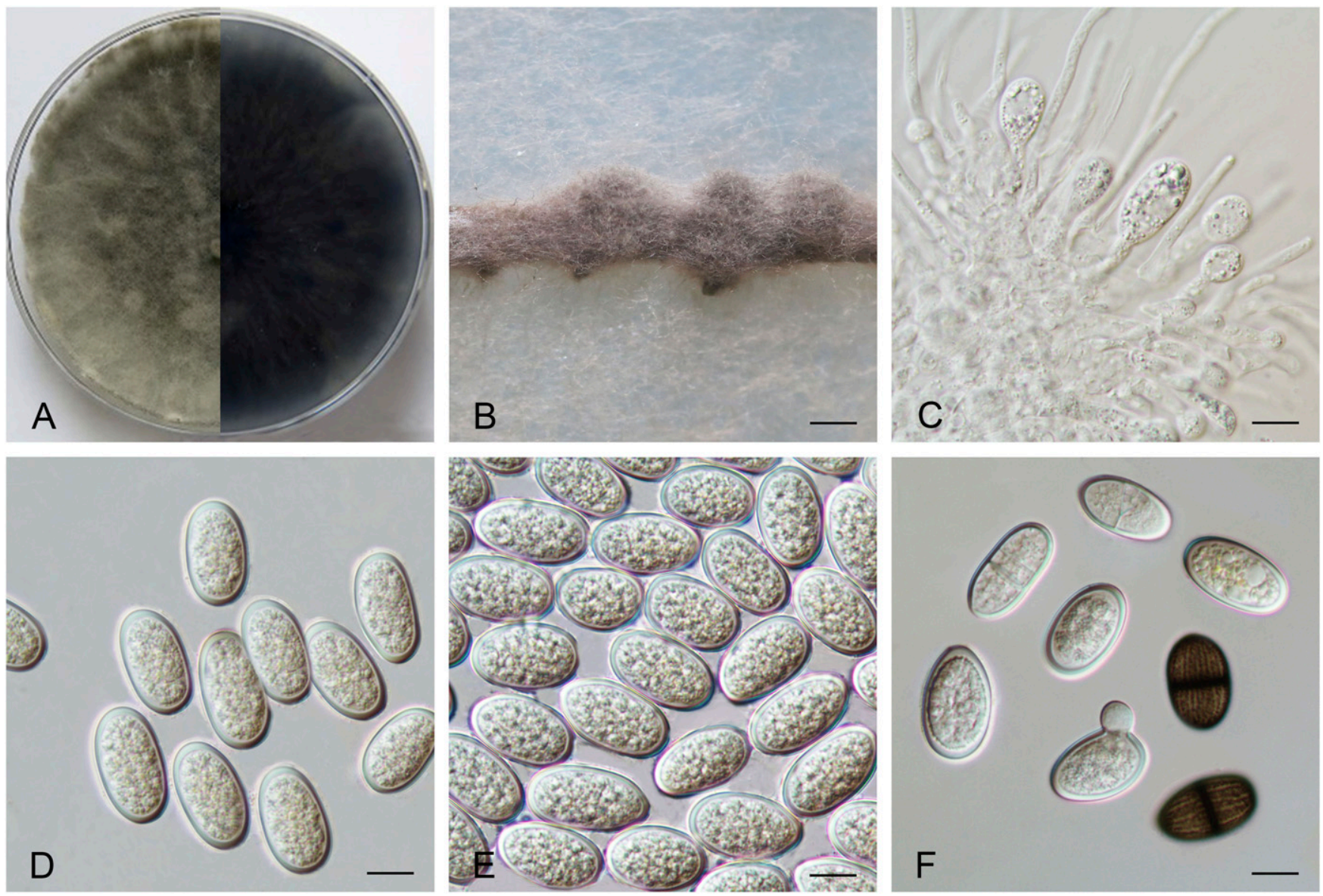

Fig. 1. Lasiodiplodia vaccinii (from ex type CGMCC3.19022). A, Colonies and reverse after 7 days on malt extract agar. B, Conidiomata formed on pine needles in culture after incubating for 3 weeks. C, Conidia developing on conidiogenous cells among paraphyses. D and E, Hyaline immature conidia. F, Germinating conidia and mature, one-septate conidia with longitudinal striations on the surface. Scale bars: $\mathbf{B}=500 \mu \mathrm{m} ; \mathbf{C}$ to $\mathbf{F}=10 \mu \mathrm{m}$. 
radial growth $(\mathrm{Xu}$ et al. 2015). Mean comparisons were conducted using Tukey's HSD $(\alpha=0.05)$ in R.

\section{Results}

Species characterization and identification. In total, 37 Botryosphaeriaceae isolates, including 12 Lasiodiplodia isolates and 25 Botryosphaeria isolates, were obtained from 36 samples (of 100 samples) collected in this study. These 25 Botryosphaeria isolates had holoblastic, hyaline, subcylindrical conidiogenous cells that were narrowly fusiform or irregularly fusiform and one-celled conidia. The size of the conidia was 18 to $21 \times 4$ to $5 \mu \mathrm{m}$, and it rarely formed a septum when senescent. All of these morphological characteristics agree with those of B. dothidea (Slippers et al. 2004). Furthermore, DNA sequence comparison of these 25 strains with the

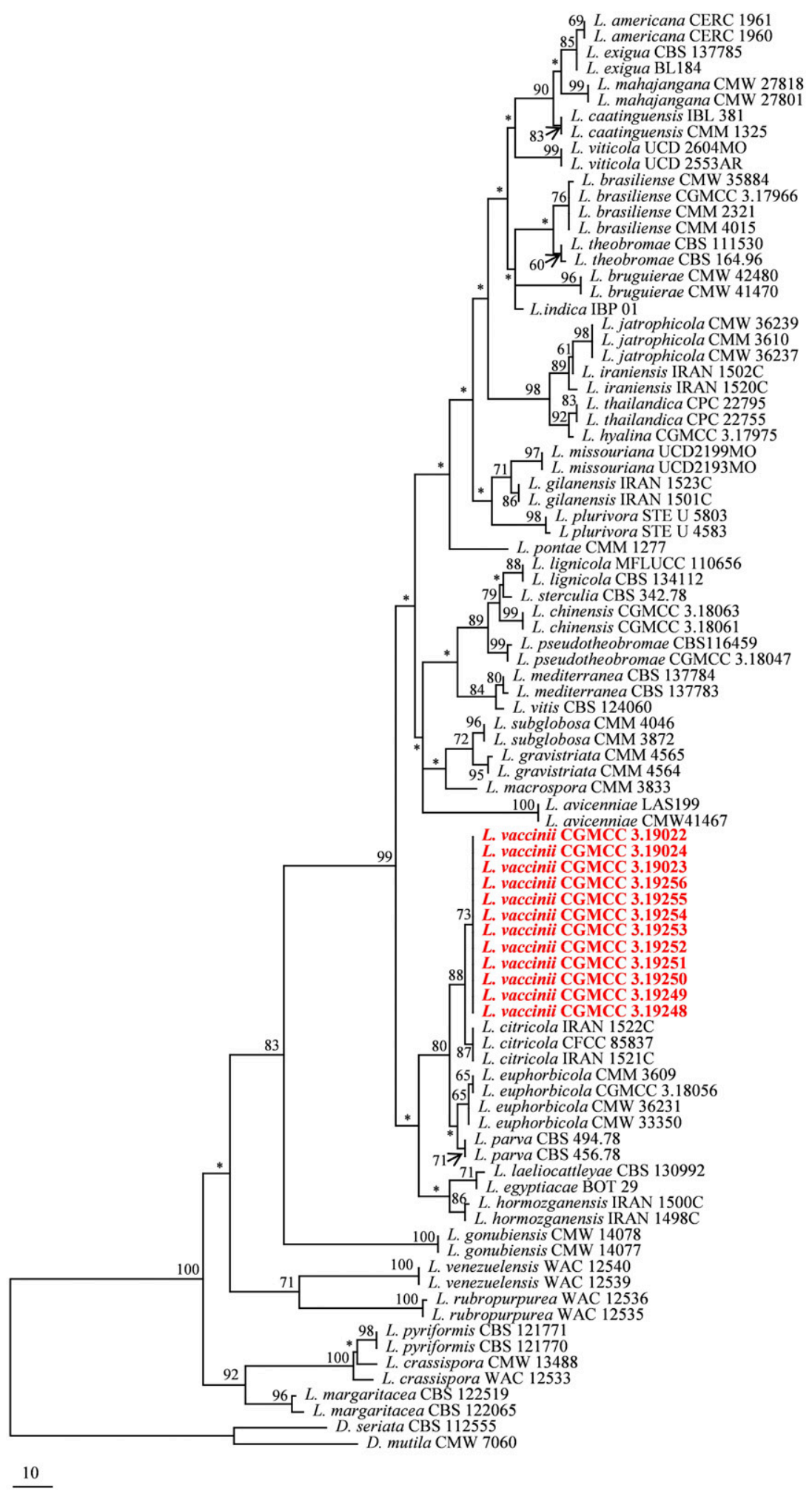

Fig. 2. Maximum parsimony tree generated from sequence analysis of the concatenated internal transcribed spacer, RNA polymerase II gene, $\beta$-tubulin gene, and translation elongation factor- $1 \alpha$ dataset. The designated outgroup taxa are Diplodia mutila and Diplodia seriata. Bootstrap support values for maximum parsimony $\geq 60 \%$ are shown above the nodes. The positions of the Lasiodiplodia vaccinii isolates are indicated in bold and red text. *Value $<60 \%$. 
ex-type strain of $B$. dothidea (CBS 115476) indicated that the identities of both the ITS and the tefl- $\alpha$ region were $99.9 \%$. The 25 Botryosphaeria isolates were thus identified as B. dothidea. Based on their morphology and the results of multigene phylogenetic analysis, the remaining 12 strains were identified as a new species of the genus Lasiodiplodia, which was named $L$. vaccinii (L. vaccinii $\mathrm{Y}$ Zhang ter \& L Zhao sp. nov., Mycobank: MB 825125, etymology: from the genus Vaccinium in reference to the host genus).

Specimens examined were China, Beijing, Huiyuan Juice Blueberry Production Garden, blighted branches of $V$. corymbosum, 6 October 2017, Y. Zhang and L. Zhao (HMAS 255366, holotype; CGMCC3.19022, ex-type living culture).

Morphological characterization. Colonies of L. vaccinii growing on MEA were initially white with moderately dense, abundant, and straight aerial mycelia growing upward to the lid of the plate; they became pale olivaceous gray to olivaceous gray within 7 days, with the reverse side black-gray. Colonies (in 90 -mm plates) reached a diameter of $31 \mathrm{~mm}$ after $24 \mathrm{~h}$ in the dark at $28^{\circ} \mathrm{C}$ and $84 \mathrm{~mm}$ after $48 \mathrm{~h}$.

Sexual stage is unknown. Conidiomata were stromatic under greyish brown mycelia and formed on both pine needles and WA medium within 15 days; they were superficial or rarely semiimmersed, black, solitary, globose with a central ostiole with or without papilla, and 770 to $1,330 \mu \mathrm{m}$ in diameter. Paraphyses were filiform, hyaline, tip rounded, initially aseptate, becoming up to one to six septate when mature, rarely branched, extending above the developing conidia layer, $\leq 88 \mu \mathrm{m}$ in length, 2 to $5 \mu \mathrm{m}$ wide. Conidiophores were not observed. Conidiogenous cells were holoblastic, hyaline, discrete, smooth thin walled, ( 9 to) 11 to 17 (to 18 ) $\times 3$ to 5 (to 6) $\mu \mathrm{m}$ (average $=$ $14.2 \times 3.9 \mu \mathrm{m}, n=20$ ). Conidia were initially hyaline; wall was

Table 2. Pathogenicity of Lasiodiplodia vaccinii and Botryosphaeria dothi$d e a$ on O'Neal blueberry plants using mycelia or conidia as inoculum 3 weeks after inoculation

\begin{tabular}{lcrr}
\hline & & \multicolumn{2}{c}{$\begin{array}{c}\text { Blueberry twigs inoculated } \\
\text { with }^{\mathbf{z}}\end{array}$} \\
\cline { 3 - 4 } Species & Isolate & Mycelia (cm) & Conidia (cm) \\
\hline L. vaccinii & CGMCC3.19022 & $15.33 \pm 1.53 \mathrm{a}$ & $16.00 \pm 7.94 \mathrm{a}$ \\
L. vaccinii & CGMCC3.19023 & $17.33 \pm 6.66 \mathrm{a}$ & $20.00 \pm 5.10 \mathrm{a}$ \\
L. vaccinii & CGMCC3.19024 & $15.67 \pm 6.03 \mathrm{a}$ & $18.17 \pm 8.89 \mathrm{a}$ \\
B. dothidea & CGMCC3.19257 & $1.73 \pm 0.46 \mathrm{~b}$ & $2.93 \pm 0.11 \mathrm{~b}$ \\
B. dothidea & CGMCC3.19258 & $1.80 \pm 0.21 \mathrm{~b}$ & $2.77 \pm 0.25 \mathrm{~b}$ \\
B. dothidea & CGMCC3.19259 & $2.03 \pm 0.31 \mathrm{~b}$ & $3.10 \pm 0.36 \mathrm{~b}$ \\
Noninoculated control & - & $0.00 \pm 0.00 \mathrm{c}$ & $0.00 \pm 0.00 \mathrm{c}$ \\
\hline D. & - &
\end{tabular}

${ }^{\mathrm{z}}$ Data followed by different letters in each column are significantly different based on honest significant difference tests at the $P<0.05$ level.

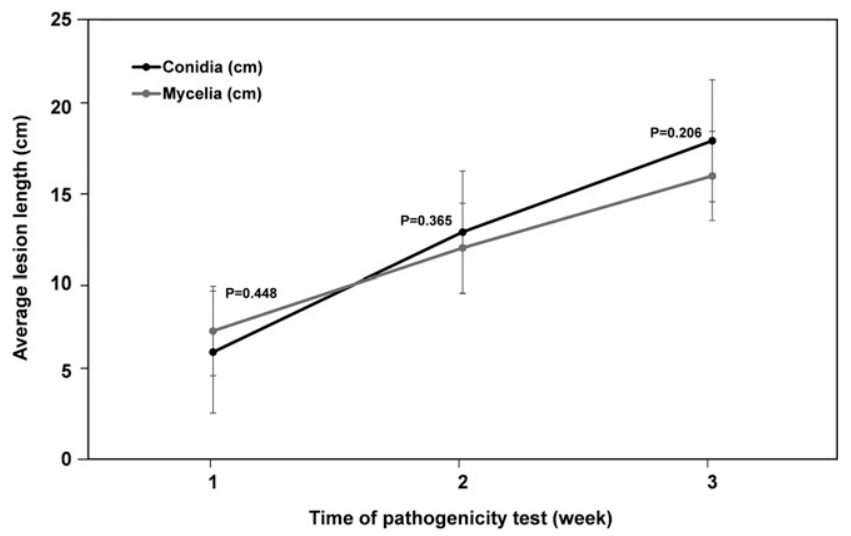

Fig. 3. Pathogenicity comparison for Lasiodiplodia vaccinii using mycelia or conidia as inocula (honest significant difference tests, $P<0.05$ ). Values are means from three isolates (CGMCC 3.19022, CGMCC 3.19023, and CGMCC 3.19024). Vertical bars indicate standard errors.
1- $\mu \mathrm{m}$ thick and ellipsoid to ovoid with rounded or slightly tapered apex, with a few turning brown with a median septum and longitudinal striations when aged: (18 to) 21 to 27 (to 31$) \times(11$ to) 12 to 14 (to 16$) \mu \mathrm{m}$ (average $=23.3 \times 12.8 \mu \mathrm{m}, n=50, \mathrm{~L} / \mathrm{W}$ ratio $=1.8$, range from 1.7 to 1.9); conidia usually germinated before septum formed (Fig. 1).

Molecular characterization. The alignment of the concatenated loci ITS, RPB2, TUB, and tefl- $\alpha$ from 90 strains (with Diplodia mutila and Diplodia seriata as the outgroup taxa) comprised 1,803 nucleotide sites, which included 1,406 constant sites, 303 parsimony-informative sites, and 94 parsimony-uninformative sites. Maximum parsimony analysis generated a total of 396 equally parsimonious trees. All trees were similar in topology and were not significantly different (not shown). One of the most parsimonious trees (tree length $=771$, consistency index $=0.637$, retention index $=$ 0.875 , rescaled consistency index $=0.557$, homoplasy index $=$ 0.363 ) is shown in Figure 2. In the phylogram, the 12 strains of $L$. vaccinii formed a terminal clade with $73 \%$ support (Fig. 2), which was sister to another terminal clade consisting of Lasiodiplodia citricola (Fig. 2). This result indicated that $L$. vaccinii is a new species, closely related to $L$. citricola.

Pathogenicity test. The three isolates of $L$. vaccinii (CGMCC3.19022, CGMCC3.19023, and CGMCC3.19024) tested in this study were pathogenic on the blueberry twigs when either mycelia or conidia were used as inocula. No symptoms were observed in the noninoculated control treatment (Table 2). Brown lesions appeared at the inoculated points 3 days after inoculation with mycelia and 5 days after inoculation with conidia. The diseased spots turned brown and lesion areas were $\leq 16-\mathrm{cm}$ long by 7 days after inoculation with both of the inocula. By 3 weeks after inoculation, the lengths of the brown necrotic lesions ranged from 8.5 to $26 \mathrm{~cm}$ for conidial inoculation and from 10 to $25 \mathrm{~cm}$ for mycelial inoculation. Over the same period, the infected xylem tissue turned light brown in both treatments. The lengths of lesions inoculated with mycelia or conidia showed no significant difference, although the average lesion length produced by a conidial suspension increased faster than that resulting from mycelial inoculation (Fig. 3). The necrotic discoloration length for $B$. dothidea was significantly shorter than that for $L$. vaccinii (Fig. 4 and Table 2).

Koch's postulates were performed by successful reisolation of fungal strains from all of the necrotic twigs inoculated with $B$. dothidea or $L$. vaccinii. The morphology and DNA sequences of the isolates retrieved from the inoculated twigs were consistent with those of the strains used for inoculations.

Effects of temperature and pH on mycelial growth. Mycelia of L. vaccinii grew on MEA in the temperature range from 15 to $40^{\circ} \mathrm{C}$ but did not grow at either 5 or $10^{\circ} \mathrm{C}$ after $48 \mathrm{~h}$ of incubation (Fig. 5). The fastest mycelial growth occurred at $30^{\circ} \mathrm{C}$, reaching $38 \mathrm{~mm}$ after $24 \mathrm{~h}$ of incubation and $90 \mathrm{~mm}$ after $48 \mathrm{~h}$ of incubation, and the least amount of growth occurred at 15 and $40^{\circ} \mathrm{C}$. No mycelial growth was observed at $15^{\circ} \mathrm{C}$ after $24 \mathrm{~h}$ of incubation, but the colony reached $10.8 \mathrm{~mm}$ after $48 \mathrm{~h}$ of incubation. The data conform to the regression equations $y=33.21-7.41 x+0.486 x^{2}-0.008 x^{3}\left(P<0.05, R^{2}=\right.$ $0.899)$ at $24 \mathrm{~h}$ of incubation and $y=62.83-16.35 x+1.18 x^{2}-$ $0.02 x^{3}\left(P<0.001, R^{2}=0.972\right)$ at $48 \mathrm{~h}$ of incubation $(x=$ temperature [degrees Celsius] and $y=$ growth [colony diameter in millimeters]) (Fig. 5). Based on regression analysis, the optimum growth of $L$. vaccinii after both 24 and $48 \mathrm{~h}$ of incubation was estimated to occur at $30.3^{\circ} \mathrm{C}$.

Mycelia of $L$. vaccinii grew on MEA in the $\mathrm{pH}$ range from 3.0 to 10.0 but did not grow at $\mathrm{pH} 2.0,11.0$, or 12.0 after $48 \mathrm{~h}$ of incubation. Mycelia grew most rapidly at $\mathrm{pH} 7.0$ after $24 \mathrm{~h}$ of incubation, reaching $38.3 \mathrm{~mm}$, followed by $\mathrm{pH} 6.0$ and 5.0, which gave colony diameters of 35.8 and $34.9 \mathrm{~mm}$, respectively. The mycelia fully covered the $90-\mathrm{mm}$ dishes after $48 \mathrm{~h}$ of incubation at $\mathrm{pH} 5.0,6.0$, and 7.0, whereas they grew more slowly at $\mathrm{pH}$ values of $3.0,4.0,8.0,9.0$, and 10.0, attaining colony diameters of $\leq 80 \mathrm{~mm}$ after $48 \mathrm{~h}$ of incubation. The data fit the regression equations $y=-48.17+30.85 x-$ $3.41 x^{2}+0.10 x^{3}\left(P<0.001, R^{2}=0.90\right)$ after $24 \mathrm{~h}$ of incubation and $y=-124.83+79.33 x-8.53 x^{2}+0.23 x^{3}\left(P<0.001, R^{2}=0.93\right)$ after $48 \mathrm{~h}$ of incubation $(x=\mathrm{pH}$ and $y=$ growth [colony diameter in 
millimeters]) (Fig. 6). Based on these regression equations, the optimal growth of L. vaccinii after 24 and $48 \mathrm{~h}$ of incubation was estimated to take place at $\mathrm{pH} 6.2$.

Effects of carbon and nitrogen sources on mycelial growth. All of the seven carbon sources tested support L. vaccinii mycelial growth (Fig. 7). After $24 \mathrm{~h}$ of incubation, the utilization of sucrose was significantly greater than that for galactose and maltose, whereas there was no difference among fructose, glucose, and sorbitol, which were slightly less well utilized than the former three carbon sources (Fig. 7). The utilization of xylose was significantly lower than that of all other carbon sources tested (Fig. 7). After $48 \mathrm{~h}$ of incubation, however, sucrose utilization was significantly higher than that of galactose, maltose, and sorbitol, whereas there was no difference between the less well-utilized fructose and glucose (Fig. 7). Xylose had the lowest level of carbon utilization (Fig. 7). All of the nitrogen sources tested could support mycelial growth (Fig. 8). After 24 and $48 \mathrm{~h}$ of incubation, the utilization of yeast extract and tryptone was significantly higher than that of glycine, ammonium nitrate, and ammonium sulfate (Fig. 8). The utilization of ammonium tartrate was significantly lower than that of all other nitrogen sources at both time points (Fig. 8).

\section{Discussion}

Phylogeny based on concatenated ITS, RPB2, TUB, and tefl- $\alpha$ DNA sequences showed that the 12 isolates of $L$. vaccinii formed a separate clade that was a sibling to other species of the genus Lasiodiplodia and closely related to L. citricola (Fig. 2). Morphologically, the paraphyses, conidiogenous cells, and conidia of $L$. vaccinii were all significantly (all $P<0.001, t$ test) narrower than those of $L$. citricola (Table 3 ). In particular, L. vaccinii could be distinguished from $L$. citricola by its short paraphyses ( $\leq 88$ versus $\leq 120 \mu \mathrm{m})$. Furthermore, the conidia of $L$. vaccinii tended to remain hyaline, and only a small proportion ( $20 \%$ after 4 weeks) of the discharged conidia became pigmented with age, in contrast with those of $L$. citricola (80\% after 4 weeks) (Abdollahzadeh et al. 2010; Dou et al. 2017a).

Pathogenicity tests were conducted on 4-year potted blueberry plants (with 2-year-old twigs) in a greenhouse with very similar conditions to those of the sampling sites. The results indicated that both
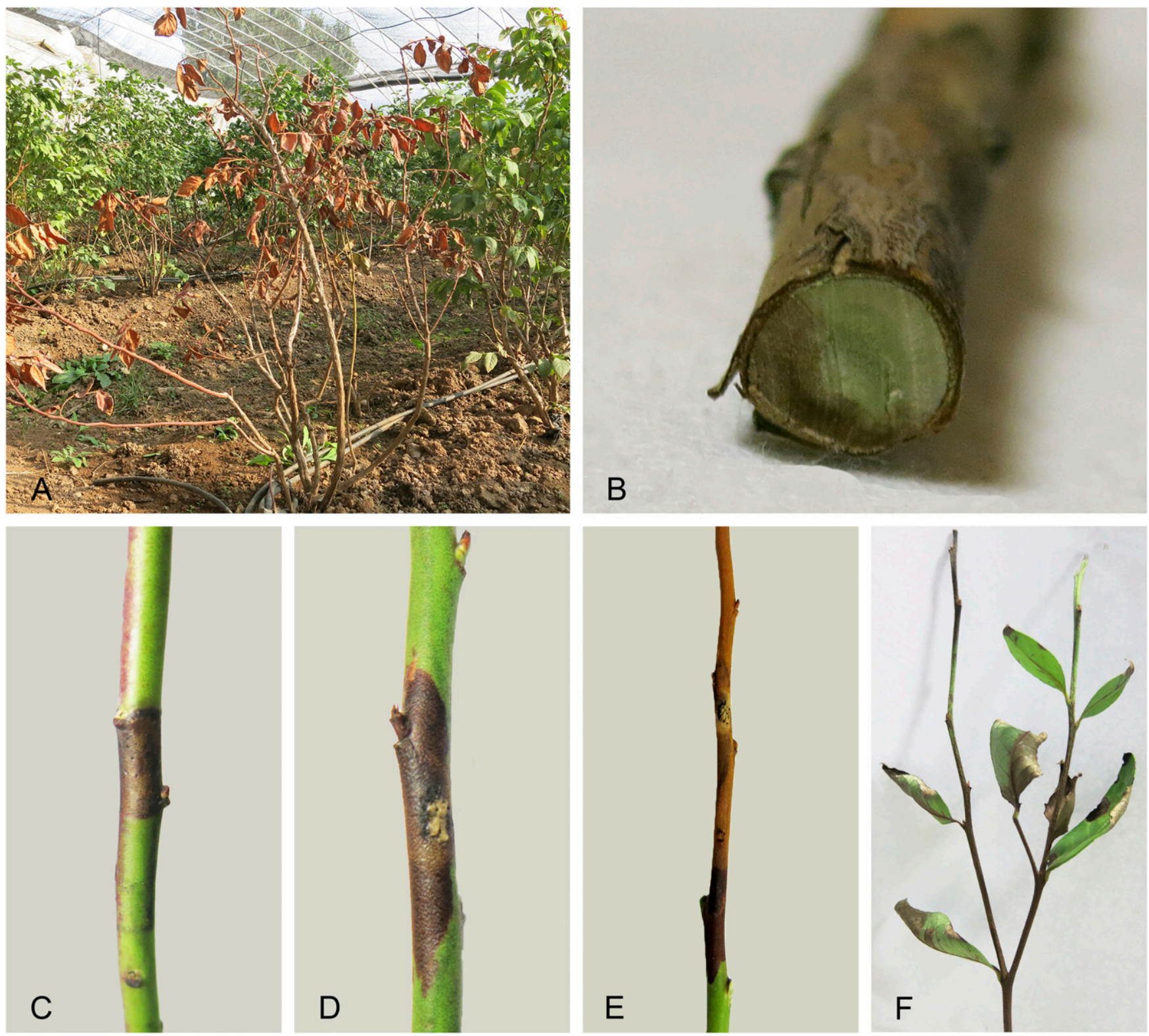

Fig. 4. Stem blight symptoms on blueberry caused by Lasiodiplodia vaccinii and Botryosphaeria dothidea. A, Death of the whole plant caused by L. vaccinii in the greenhouse. B, Stem blight caused by $L$. vaccinii in the greenhouse. C, Symptoms 3 weeks after inoculating with conidia of $B$. dothidea. Symptoms $D, 2$ and E, 3 weeks after inoculating with conidia of $L$. vaccinii. $F$, Symptoms on blueberry twig 3 weeks after inoculating with mycelium of $L$. vaccinii. 
$L$. vaccinii and $B$. dothidea were pathogenic on blueberry twigs. $L$. vaccinii invaded the xylem and caused mortality of the whole branch within 3 weeks, showing the typical stem blight that occurred in the sampled greenhouse. By contrast, $B$. dothidea, however, turned the infected twig tissue dark brown, but the plants were still surviving 3 weeks after inoculation. Xu et al. (2015) also reported that Lasiodiplodia spp. were more virulent than Botryosphaeria spp. in blueberries.

A number of botryosphaeriaceous species have been reported to cause stem blight of blueberries, including $B$. dothidea and $L$. theobromae in southeastern United States (Creswell and Milholland

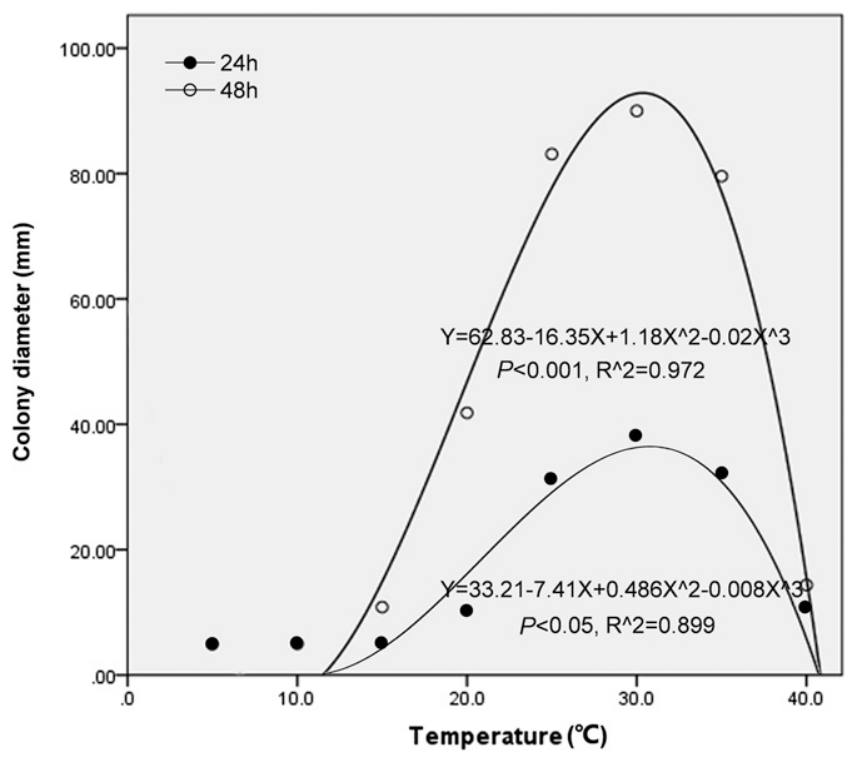

Fig. 5. Regression curves and equations for mycelial growth of Lasiodiplodia vaccinii after incubation for 24 and $48 \mathrm{~h}$ at $5,10,15,20,25,30,35$, and $40^{\circ} \mathrm{C}$ on malt extract agar medium ( $x=$ temperature [degrees Celsius] and $y=$ growth [colony diameter in millimeters]). Optimal mycelial growth temperature was estimated to be $30.3^{\circ} \mathrm{C}$.

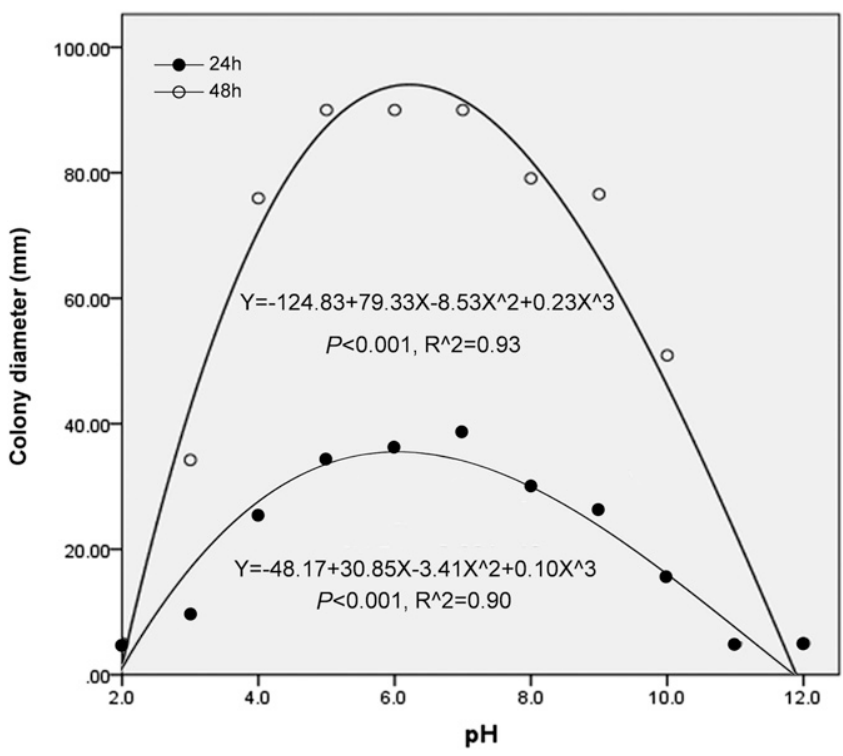

Fig. 6. Regression curves and equations for mycelial growth of Lasiodiplodia vaccinii after incubation for 24 and $48 \mathrm{~h}$ at pH 2.0, 3.0, 4.0, 5.0, 6.0, 7.0, 8.0, 9.0, 10.0, 11.0, and 12.0 on malt extract agar medium $(x=\mathrm{pH}$ and $y=$ growth [colony diameter in millimeters]). Optimum mycelial growth $\mathrm{pH}$ was estimated to be 6.2 .
1988; Milholland 1972b; Witcher and Clayton 1962), N. parvum in California in the United States and in Mexico (Boyzo-Marin et al. 2016; Koike et al. 2014), Neofusicoccum ribis in Florida in the United States and in New Zealand (Tennakoon et al. 2018; Wright and Harmon 2010), and Macrophomina phaseolina in Serbia (Popović et al. 2018). In China, B. dothidea, N. parvum, L. theobromae, and $L$. pseudotheobromae have all been reported as causing blueberry stem blight (Wang et al. 2016; Xu 2016; Xu et al. 2015; Yu et al. 2012, 2013a, b). Among these species, $B$. dothidea was the most widely reported from temperate to subtropical areas of China, such as Liaoning, Shandong, Jiangsu, Zhejiang, Fujian, Yunnan, and Sichuan provinces (Xu 2016; Xu et al. 2015; Yu et al. 2012). N. parvum is mainly distributed in subtropical areas of China, such as Yunnan, Sichuan, Zhejiang, and Fujian (Xu 2016; $\mathrm{Xu}$ et al. 2015; Yu et al. 2013a, b). L. theobromae and $L$. pseudotheobromae have been mostly reported in tropical or subtropical areas of China, including Jiangsu and Zhejiang provinces, and only rarely in temperate areas of China, such as Shandong province (Wang et al. 2016; Xu 2016; Xu et al. 2015). The causal agents of stem blight caused by the Botryosphaeriaceae differ among locations worldwide, and this is probably because of the different environmental conditions, such as temperature and humidity, and the influence of management practices (Tennakoon et al. 2018).

The growth temperature for phytopathogenic fungi is generally from 10 to $35^{\circ} \mathrm{C}$, with the optima from 20 to $30^{\circ} \mathrm{C}$. For instance, the optimal growth temperature of Penicillium cellarum was reported as $22^{\circ} \mathrm{C}$ (Strausbaugh and Dugan 2017), that for Diaporthe neotheicola and Diaporthe ambigua was $25^{\circ} \mathrm{C}$, the optimum for Diaporthe sp. was $22^{\circ} \mathrm{C}$ (Elfar et al. 2013), and that for Phoma sorghina was 20 to $25^{\circ} \mathrm{C}$ (Lin et al. 2015). The mycelium of L. vaccinii, however, grew from 15 to $40^{\circ} \mathrm{C}$, with the optimal temperature being $30.3^{\circ} \mathrm{C}$. Similar results have been reported for the type species of the genus Lasiodiplodia, L. theobromae, which showed growth at higher temperatures $\left(15\right.$ to $\left.40^{\circ} \mathrm{C}\right)$ and a higher optimal temperature $\left(29\right.$ to $30^{\circ} \mathrm{C}$ ) than most phytopathogens. Members of some other genera of the Botryosphaeriaceae, such as $N$. ribis and $B$. dothidea, have lower optimal $\left(27\right.$ to $\left.29^{\circ} \mathrm{C}\right)$ and growth $(15$ to $35^{\circ} \mathrm{C}$ ) temperatures (Wright and Harmon 2010; Xu et al. 2015). The relatively high growth temperature ranges and optimal temperatures for Lasiodiplodia spp. may help to explain their dominant distribution in tropical or subtropical areas as well as the occurrence of $L$. vaccinii in the Beijing greenhouse, where the temperature and humidity are high.

Most phytopathogenic fungi grow optimally in a $\mathrm{pH}$ range between 5 and 6.5 (Cochrane 1958; Lin et al. 2015). The optimal pH value for L. vaccinii was from 5.0 to 7.0, although it could still grow slowly at $\mathrm{pH}$ values of 4.0 or 10.0. Similar results have been reported for $L$. theobromae, which could grow on media with a $\mathrm{pH}$ range from 4.0 to 10.0 , with the optimal $\mathrm{pH}$ being in the range from 5.0 to 7.0 (Xu 2016). The optimal growth $\mathrm{pH}$ value of $B$. dothidea, however, has been found to range from 5.0 to 8.0 , and it grew more slowly than L. theobromae or L. vaccinii (Xu 2016).

All of the seven carbon sources tested in this study could support the growth of $L$. vaccinii, although the utilization of xylose was less than that of all of the other six carbon sources. Xu et al. (2015), however, reported that $L$. theobromae has a high-xylose utilization rate (the diameter of the fungal colony reached $90 \mathrm{~mm}$ after $48 \mathrm{~h}$ of incubation). $L$. vaccinii could use all of the nitrogen sources tested in this study, which is similar to findings for L. theobromae (Xu 2016). Although $L$. theobromae can also use yeast extract, tryptone, ammonium sulfate, ammonium tartrate, ammonium nitrate, and glycine, its ability to utilize ammonium salts (ammonium sulfate, ammonium tartrate, and ammonium nitrate) was lower than that of $L$. vaccinii (Xu 2016).

L. vaccinii has been found only in greenhouse farms in the suburban Beijing area. Management practices, including better ventilation and lighting, might help to alleviate the damage resulting from stem blight caused by L. vaccinii. The distribution and host spectrum of L. vaccinii need additional study. 


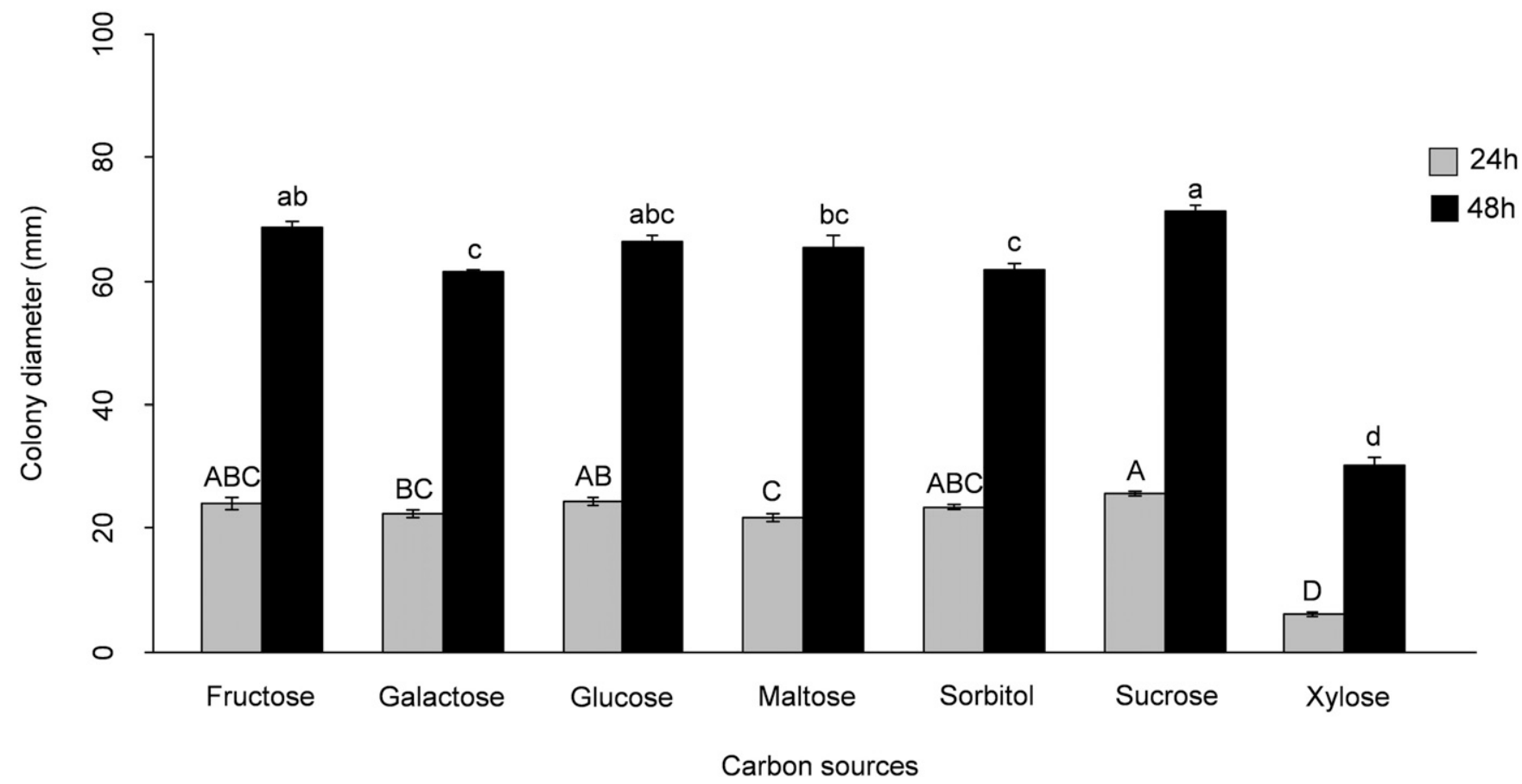

Fig. 7. Effects of carbon source on growth of Lasiodiplodia vaccinii mycelium. Bars with different uppercase or lowercase letters represent significant differences after 24 and $48 \mathrm{~h}$ of incubation, respectively, according to honest significant difference tests at the $P<0.05$ level.

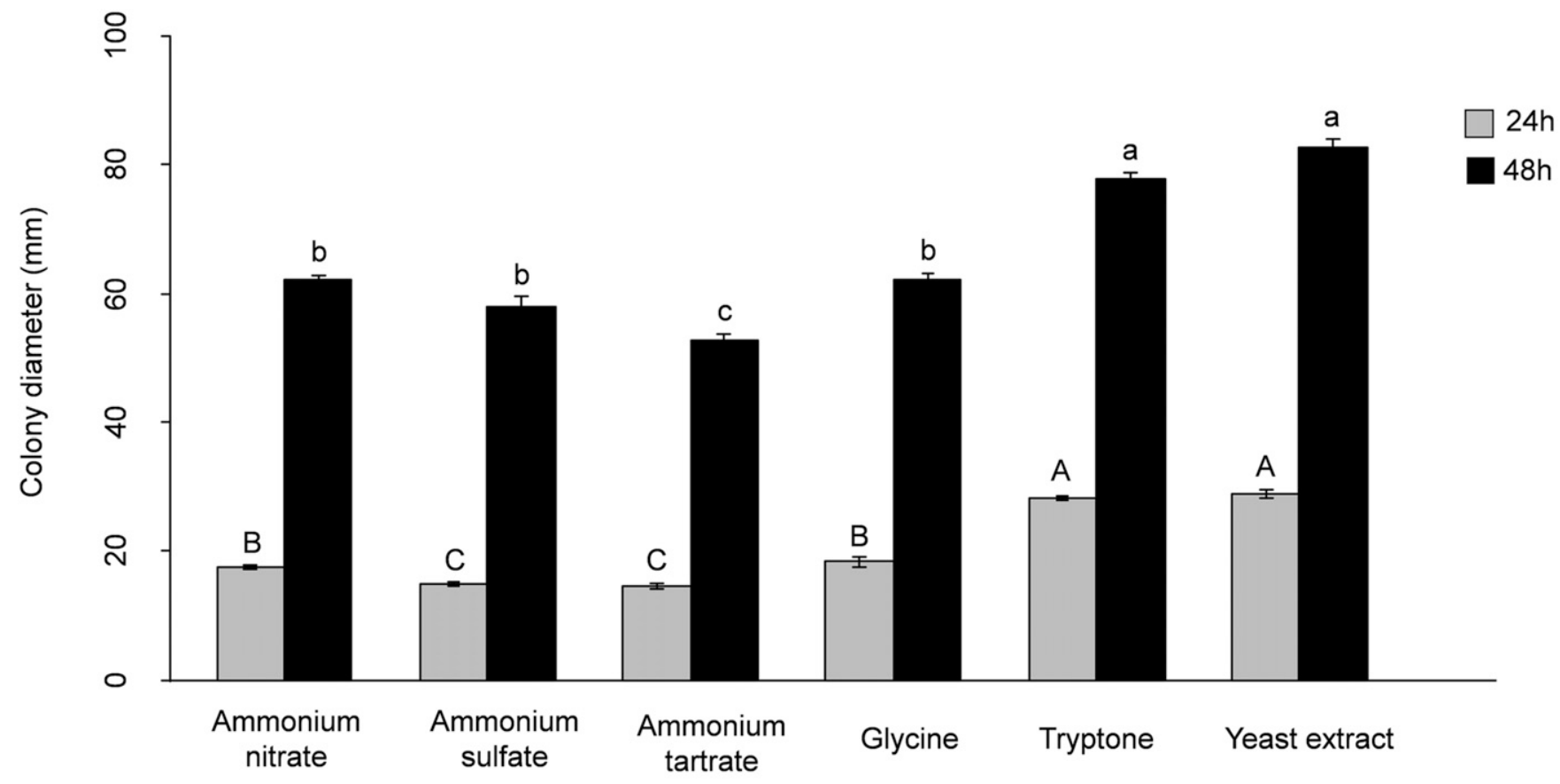

\section{Nitrogen sources}

Fig. 8. Effects of nitrogen source on growth of Lasiodiplodia vaccinii mycelium. Bars with different uppercase or lowercase letters represent significant differences after 24 and $48 \mathrm{~h}$ of incubation, respectively, according to honest significant difference tests at the $P<0.05$ level.

Table 3. A morphological comparison of Lasiodiplodia vaccinii and Lasiodiplodia citricola

\begin{tabular}{lccccc}
\hline Species & $\begin{array}{c}\text { Width of paraphyses } \\
(\boldsymbol{\mu} \text {; mean } \pm \mathbf{S D})^{\mathbf{z}}\end{array}$ & $\begin{array}{c}\text { Length of conidiogenous } \\
\text { cells }(\boldsymbol{\mu} \text {; mean } \pm \mathbf{S D})\end{array}$ & $\begin{array}{c}\text { Width of conidiogenous cells } \\
(\boldsymbol{\mu} \text {; } \text { mean } \pm \text { SD })\end{array}$ & $\begin{array}{c}\text { Length of conidia } \\
(\boldsymbol{\mu m} ; \text { mean } \pm \text { SD) }\end{array}$ & $\begin{array}{c}\text { Width of conidia } \\
(\boldsymbol{\mu m} ; \boldsymbol{m e a n} \pm \mathbf{S D})\end{array}$ \\
\hline L. vaccinii & $2.98 \pm 0.48 \mathrm{~b}$ & $14.38 \pm 2.10 \mathrm{a}$ & $3.89 \pm 0.81 \mathrm{~b}$ & $23.30 \pm 2.56 \mathrm{a}$ & $12.80 \pm 0.94 \mathrm{~b}$ \\
L. citricola & $3.68 \pm 0.62 \mathrm{a}$ & $14.18 \pm 2.11 \mathrm{a}$ & $4.69 \pm 0.74 \mathrm{a}$ & $23.18 \pm 1.41 \mathrm{a}$ & $13.30 \pm 0.67 \mathrm{a}$ \\
\hline
\end{tabular}

${ }^{\mathrm{z}} \mathrm{SD}$, standard deviation. 


\section{Literature Cited}

Abdollahzadeh, J., Javadi, A., Goltapeh, E. M., Zare, R., and Phillips, A. J. 2010. Phylogeny and morphology of four new species of Lasiodiplodia from Iran. Persoonia 25:1-10.

Alves, A., Crous, P. W., Correia, A., and Phillips, A. J. L. 2008. Morphological and molecular data reveal cryptic species in Lasiodiplodia theobromae. Fungal Divers. 28:1-13.

Boyzo-Marin, J., Rebollar-Alviter, A., Silva-Rojas, H. V., and RamirezMaldonado, G. 2016. First report of Neofusicoccum parvum causing stem blight and dieback of blueberry in Mexico. Plant Dis. 100:2524.

Carbone, I., Anderson, J. B., and Kohn, L. M. 1999. A method for designing primer sets for the speciation studies in filamentous ascomycetes. Mycologia 91:553-556.

Chen, S. F., Li, G. Q., Liu, F. F., and Michailides, T. J. 2015. Novel species of Botryosphaeriaceae associated with shoot blight of pistachio. Mycologia 107: 780-792.

Chen, S. F., Morgan, D. P., and Michailides, T. J. 2014. Botryosphaeriaceae and Diaporthaceae associated with panicle and shoot blight of pistachio in California, USA. Fungal Divers. 67:157-179.

Cochrane, V. W. 1958. Physiology of Fungi. John Wiley \& Sons, New York.

Creswell, T. C., and Milholland, R. D. 1988. Spore release and infection periods of Botryosphaeria dothidea on blueberry in North Carolina. Plant Dis. 72: 342-346.

Cruywagen, E. M., Slippers, B., Roux, J., and Wingfield, M. J. 2017. Phylogenetic species recognition and hybridisation in Lasiodiplodia: A case study on species from baobabs. Fungal Biol. 121:420-436.

Czapek, F. 1902. Untersuchungen über die stickstoffgewinnung und eiweissbildung der pflanzen. Beitr. Chem. Physiol. Pathol. 1:538-560.

Czapek, F. 1903. Untersuchungen über die stickstoffgewinnung und eiweifsbildung der schimmelpilze. Beitr. Chem. Physiol. Pathol. 3:47-66.

Dou, Z. P., He, W., and Zhang, Y. 2017a. Does morphology matter in taxonomy of Lasiodiplodia? An answer from Lasiodiplodia hyalina sp. nov. Mycosphere 8: 1014-1027.

Dou, Z. P., He, W., and Zhang, Y. 2017b. Lasiodiplodia chinensis, a new holomorphic species from China. Mycosphere 8:521-532.

Dox, A. W. 1910. The Intracellular Enzymes of Penicillium and Aspergillus: With Special Reference to Those of Penicillium camemberti. USDA Bureau of Animal Industry, Washington, DC.

Elfar, K., Torres, R., Díaz, G. A., and Latorre, B. A. 2013. Characterization of Diaporthe australafricana and Diaporthe spp. associated with stem canker of blueberry in Chile. Plant Dis. 97:1042-1050.

Espinoza, J. G., Briceño, E. X., Chávez, E. R., Úrbez-Torres, J. R., and Latorre, B. A. 2009. Neofusicoccum spp. associated with stem canker and dieback of blueberry in Chile. Plant Dis. 93:1187-1194.

Evans, E. A., and Ballen, F. H. 2014. An overview of US blueberry production, trade, and consumption, with special reference to Florida. University of Florida, IFAS, Extension, FE952.

Glass, N. L., and Donaldson, G. C. 1995. Development of primer sets designed for use with the PCR to amplify conserved genes from filamentous ascomycetes. Appl. Environ. Microbiol. 61:1323-1330.

Koike, S. T., Rooneylatham, S., and Wright, A. F. 2014. First report of stem blight of blueberry in California caused by Neofusicoccum parvum. Plant Dis. 98:1280.

Kong, C. S., Qiu, X. L., Yi, K. S., Yu, X. F., and Yu, L. 2010. First report of Neofusicoccum vitifusiforme causing blueberry blight of blueberry in China. Plant Dis. 94:1373.

Li, Y. D., Sun, H. Y., and Chen, L. 2016. China blueberry industry development report. China Fruits. 5:1-10.

Lin, Y. L., Huang, L. L., Suolang, L. M., Gao, X. N., Chen, Y. C., and Kang, Z. S. 2011. A rapid laboratory evaluation system for apple ring rot. Acta Phytopathol. Sin. 38:37-41.

Lin, Z. Y., Wei, J. J., Zhang, M. Q., Xu, S. Q., Guo, Q., Wang, X., Wang, J. H., Chen, B. S., Que, Y. X., Deng, Z. H., Chen, R. K., and Powell, C. A. 2015. Identification and characterization of a new fungal pathogen causing twisted leaf disease of sugarcane in China. Plant Dis. 99:325-332.

Michailides, T. J., and Morgan, D. P. 1992. Effects of temperature and wetness duration on infection of pistachio by Botryosphaeria dothidea and management of disease by reducing duration of irrigation. Phytopathology 82:1399-1406

Michailides, T. J., and Morgan, D. P. 2004. Panicle and shoot blight of pistachio: A major threat to the California pistachio industry. APSnet Feature. doi:10.1094/ APSnetFeature-2004-0104

Milholland, R. D. 1972a. Factors affecting sporulation and infection by the blueberry stem canker fungus, Botryosphaeria corticis. Phytopathology 62: 137-139.

Milholland, R. D. 1972b. Histopathology and pathogenicity of Botryosphaeria dothidea on blueberry stems. Phytopathology 62:654-660.
Page, R. D. 1996. TREEVIEW: An application to display phylogenetic trees on personal computers. Comput. Appl. Biosci. 12:357-358.

Pavlic, D., Slippers, B., Coutinho, T. A., Gryzenhout, M., and Wingfield, M. J. 2004. Lasiodiplodia gonubiensis sp. nov. a new Botryosphaeria anamorph from native Syzygium cordatum in South Africa. Stud. Mycol. 50:313-322.

Phillips, A. J. L., Alves, A., Abdollahzadeh, J., Slippers, B., Wingfield, M. J., Groenewald, J. Z., and Crous, P. W. 2013. The Botryosphaeriaceae: Genera and species known from culture. Stud. Mycol. 76:51-167.

Phillips, A. J. L., Oudemans, P. V., Correia, A., and Alves, A. 2006. Characterisation and epitypification of Botryosphaeria corticis, the cause of blueberry cane canker. Fungal Divers. 21:141-155.

Popović, T., Blagojević, J., Aleksić, G., Jelušić, A., Krnjajić, S., and Milovanović, P. 2018. A blight disease on highbush blueberry associated with Macrophomina phaseolina in Serbia. Can. J. Plant Pathol. 40:121-127.

Shi, H. Z., and Liu, H. M. 2009. The current research situation of blueberry. J. Jiangsu For. Sci. Technol. 36:48-51.

Slippers, B., Crous, P. W., Denman, S., Coutinho, T. A., Wingfield, B. D., and Wingfield, M. J. 2004. Combined multiple gene genealogies and phenotypic characters differentiate several species previously identified as Botryosphaeria dothidea. Mycologia 96:83-101.

Slippers, B., and Wingfield, M. J. 2007. Botryosphaeriaceae as endophytes and latent pathogens of woody plants: Diversity, ecology and impact. Fungal Biol. Rev. 21:90-106.

Smith, B. J. 2004. Susceptibility of southern highbush blueberry cultivars to Botryosphaeria stem blight. Small Fruits Rev. 3:193-201.

Strausbaugh, C. A., and Dugan, F. 2017. A novel Penicillium sp. causes rot in stored sugar beet roots in Idaho. Plant Dis. 101:1781-1787.

Swofford, D. L. 2002. PAUP*: Phylogenetic Analysis Using Parsimony (*and Other Methods), version 4.0b10. Sinauer Associates, Sunderland, MA.

Tamura, K., Stecher, G., Peterson, D., Filipski, A., and Kumar, S. 2013. MEGA6: Molecular evolutionary genetics analysis version 6.0. Mol. Biol. Evol. 30: $2725-2729$.

Tang, W., Ding, Z., Zhou, Z. Q., Wang, Y. Z., and Guo, L. Y. 2012. Phylogenetic and pathogenic analyses show that the causal agent of apple ring rot in China is Botryosphaeria dothidea. Plant Dis. 96:486-496.

Tennakoon, K. M. S., Ridgway, H. J., Jaspers, M. V., and Jones, E. E. 2018 Factors affecting Neofusicoccum ribis, infection and disease progression in blueberry. Eur. J. Plant Pathol. 151:87-99.

van Niekerk, J. M., Crous, P. W., (Ewald) Groenewald, J. Z., Fourie, P. H., and Halleen, F. 2004. DNA phylogeny, morphology and pathogenicity of Botryosphaeria species on grapevines. Mycologia 96:781-798.

Wang, J. N., Zhao, H. H., Ying-Ying, Y. U., Xiao-Dong, L. I., Liang, C., and BaoDu, L. I. 2016. The pathogen causing Lasiodiplodia twig blight of blueberry. Mycosystema 35:657-665.

White, T. J., Bruns, T., Lee, S., and Taylor, J. 1990. Amplification and direct sequencing of fungal ribosomal RNA genes for phylogenetics. Pages 315-322 in: PCR Protocols: A Guide to Methods and Applications, M. A Innis, D. H. Gelfand, J. J. Sminsky, and T. J. White, eds. Academic Press, New York, NY.

Witcher, W., and Clayton, C. N. 1962. Blueberry stem blight caused by Botryosphaeria dothidea. Phytopathology 53:705-712.

Wright, A. F., and Harmon, P. F. 2009. First report of Lasiodiplodia theobromae associated with stem blight of southern highbush blueberries in Florida. Plan Dis. 93:962.

Wright, A. F., and Harmon, P. F. 2010. Identification of species in the Botryosphaeriaceae family causing stem blight on southern highbush blueberry in Florida. Plant Dis. 94:966-971.

$\mathrm{Xu}$, C. N. 2016. Etiology, Molecular Detection and Control of Blueberry Stem Blight in China. Hebei Agricultural University, Baoding, China.

Xu, C. N., Zhang, H. J., Zhou, Z. S., Hu, T., Wang, S. T., Wang, Y. N., and Cao, K Q. 2015. Identification and distribution of Botryosphaeriaceae species associated with blueberry stem blight in China. Eur. J. Plant Pathol. 143: 737-752.

Yu, L., Impaprasert, R., Zhao, J. R., Xu, S. G., and Wu, X. 2013a. Stem dieback of highbush blueberries caused by Neofusicoccum parvum in China. New Dis. Rep. 27:3.

Yu, L., Rasisara, I., Xu, S. G., Wu, X., and Zhao, J. R. 2012. First report of stem blight of blueberry caused by Botryosphaeria dothidea in China. Plant Dis. 96 1697.

Yu, L., Zhao, J. R., Impaprasert, R., Xu, S. G., and Wu, X. 2013b. Identification of the pathogen causing twigs and stem dieback in blueberry. Acta Phytopathol Sin. 43:421-425

Zhang, Y., Wang, H. K., Fournier, J., Crous, P. W., Jeewon, R., Pointing, S. B., and Hyde, K. D. 2009. Towards a phylogenetic clarification of Lophiostomal Massarina and morphologically similar genera in the Pleosporales. Fungal Divers. 38:225-251 